\title{
New Electromagnetic Imaging Tool Introduced for Corrosion Detection
}

\author{
Xingfu Zhong ${ }^{1 a}$ Yingxing $\mathrm{Wu}^{1}$ Jianqiao $\mathrm{Chen}^{2 \mathrm{~b}} \mathrm{~A}$. Abakumov ${ }^{3 \mathrm{C}}$ \\ ${ }^{1}$ Institute of Mechanics, CAS, Beijing 100190 \\ ${ }^{2}$ China Petroleum Logging, LTD., CNPC, Beijing, 100120 \\ ${ }^{3}$ Intros Co LLC, Russia, Moscow, 249032 \\ ae-mail: xfzhong@imech.ac.cn, ${ }^{\mathrm{b} e} \mathrm{e}-\mathrm{mail}$ : chenjianqiao@sina.com, \\ ce-mail: AlexAbakumov@yandex.ru
}

\begin{abstract}
Keywords: magnetic flux leakage, casing well, corrosion inspection
\end{abstract}
\begin{abstract}
The new Electromagnetic Imaging Tool (EMIT) is introduced in this study. It is also described that the basic inspection theory, system structure and applications. The EMIT can determine whether metal loss or casing damage has occurred internally or externally. A 3D casing image can be supplied, including horizontal, vertical profile. The experimental results show that the EMIT has a "high-resolution" for MFL method in the casing well because of the steel brush structure. The minimal diameter of the inspection hole is $4 \mathrm{~mm}$, and the thickness determination error of casing wall is $0.4 \mathrm{~mm}$. A number of examples from oilfield are presented.
\end{abstract}

\section{Introduction}

The integrity of casing well is a very important component in the safe operations of oil and gas wells. Casing corrosion can take the form of internal or external pitting and general wall loss or thinning. The following are important technical objectives of oil production companies:

1. to provide evaluation of technical condition of wells for effective scheduling of maintenance

2. to chose production modes of wells suitable for their technical condition

3 . to determine efficient methods of corrosion protection

Various methods exist to evaluate casing integrity, all with inherent strengths and weaknesses, such as caliper [1], ultrasonic [2, 3], eddy current [4], and magnetic flux leakage (MFL) [5, 6]. The new Electromagnetic Imaging Tool (EMIT) is a MFL device [7]. It provides a means of evaluating the condition of casing, and the scanning Imaging has a high resolution. It can inspect $4 \mathrm{~mm}$ hole in the casing wall. The "high-resolution" of the new MFL method is based on linear Hall elements and steel brush, electronic and mechanical configuration of the inspection system. These developments are intended to produce a more accurate determination of defect the damage on casing. It would provide operators with improved data for casing integrity management.

\section{Principle of Measurement}

The EMIT utilizes method of the magnetic flux leakage. Its detector consists of two units, a magnetizing unit and a pick-up sensor unit. When the casing wall is magnetized, the magnetic line of force passes through the casing wall. If the casing exist defect, such as figure 1, the magnetic line of force are distorted, and shaped as a distortion magnetic field caused by defect.

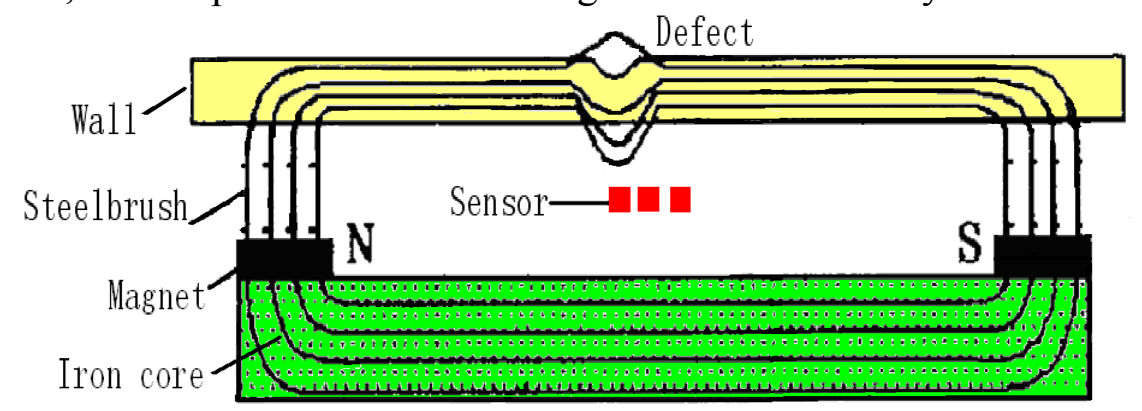

Fig. 1 The magnetic flux leakage sketch. 
This distortion magnetic field is detected by sensor of the Hall elements. When detector is moved, the signal of distortion magnetic is recorded. The amplitude of this signal indicates the size and distribution of the defect. Usually, the amplitude is influenced by five factors: thickness of casing wall, casing diameter, environmental temperature, magnetic permeability and resistivity of the metal. The most important is the distortion signal directly proportional to the defects and the MFL signal proportional to the thickness of casing wall.

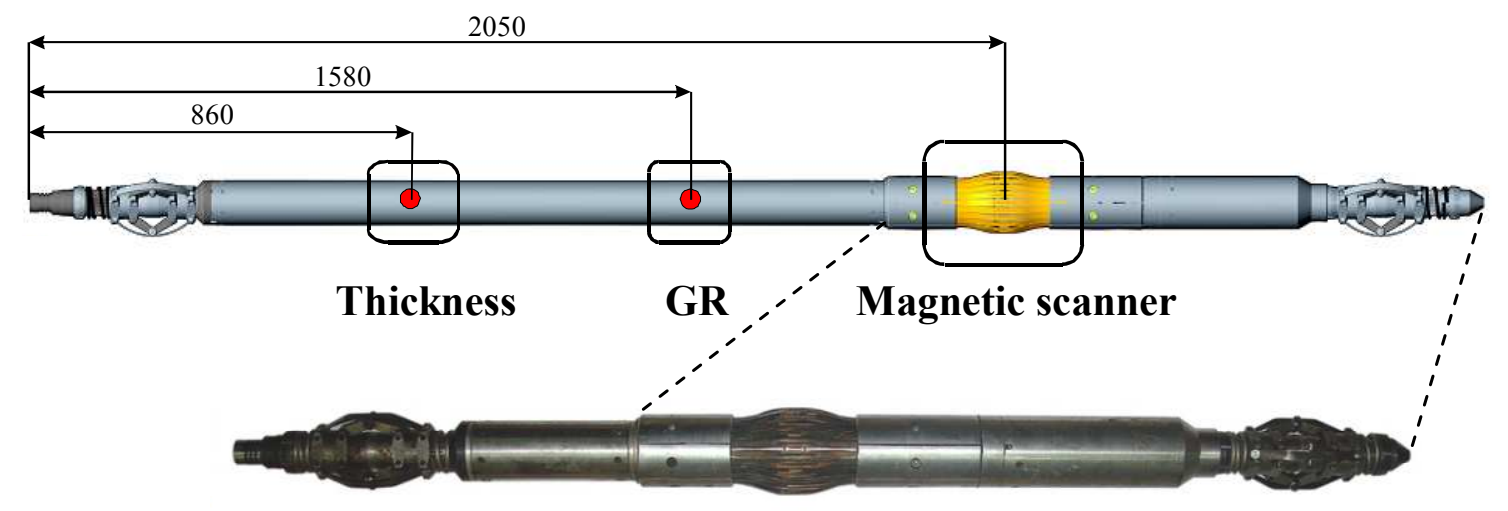

Fig. 2 The EMIT structure and its picture.

The structure and specifications

The EMIT module consists of three units, the scanner of magnetic unit, the thickness of magnetic unit, and the gamma-ray (GR) unit. The scanner of magnetic unit likes an introscope. It determines details of the casing defects. The thickness unit determines the thickness and the average circumference of casing wall. The GR unit is used to depth correction. It detects radioactive abnormal of the formation, and might be a sign of fluid leaking outside the casing at damaged area. The figure 2 shows the EMIT structure and picture. Its specifications are presented in Table 1.

Table 1. The EMIT specifications

\begin{tabular}{|l|l|}
\hline Parameter & Value \\
\hline Recording speed, m/hour: & 200 \\
\hline Maximal hydrostatic pressure, MPa. & 80 \\
\hline Maximal operational temperature, ${ }^{\circ} \mathrm{C}$ & 100 \\
\hline Maximal power consumption, Wt & 600 \\
\hline diameter x length, mm & 114 x 3100 \\
\hline weight, kg: & 100 \\
\hline Minimal diameter of detected hole, mm & 4 \\
\hline Minimal size of detected “cross-crack" type defect: & \\
\hline - Length/opening, mm & $30 / 10$ \\
\hline • Depth, \% of the wall thickness & 20 \\
\hline Minimal size of detected "corrosion cavity": & \\
\hline - Length/width, mm & $10 / 10$ \\
\hline • Depth, \% of the wall thickness & 40 \\
\hline Maximal casing wall thickness, mm & 11 \\
\hline Determination error of the casing wall thickness, mm & 0.4 \\
\hline
\end{tabular}

\section{Interpretation software}

The interpretation software is used data processing. The processing data includes parameter adjustment of the casing defects, details presentation of defects, orthography and 3D imaging, data storage and transformation. The processing result can be transformed two formats: LAS and 
graphic. The function of imaging editing is to supply printing images and storage. The software capability of data processing is being constantly perfected, and as it is updated, the latest software versions are actualized. The software realizes the following functions:

1) Depth correction, calibration of indications, and adjustment of scanning imaging data.

2) Data diagnosis of recording, checking completeness and quality of the data for magnetic scanner, magnetic thickness and gamma-ray.

3) Checking details of defects, data interpretation and result report.

4) Pre-processing data, eliminating of influencing factors, distorting filtration, and correcting failures of system.

Figure 3 show the result of the Interpretation software. We observed the 3D image and its unfold graph, Figure $3 \mathrm{a}$ is a casing shape and casing corrosion. Figure $3 \mathrm{~b}$ is perforation holes in the casing. Figure $3 \mathrm{c}$ is casing damage at perforation zone. By the way, the collar is a short pipe with thread inside, it links two pipes together. In the process of geophysics work during casing inspection, the diagnosis data are stored to the PC memory, and the current diagnostic data are presented on the monitor.

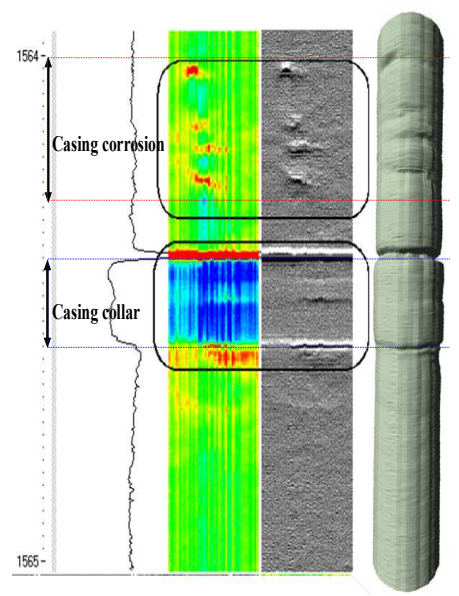

a

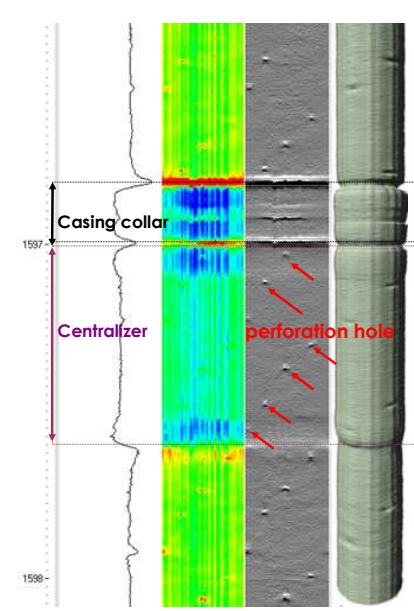

b

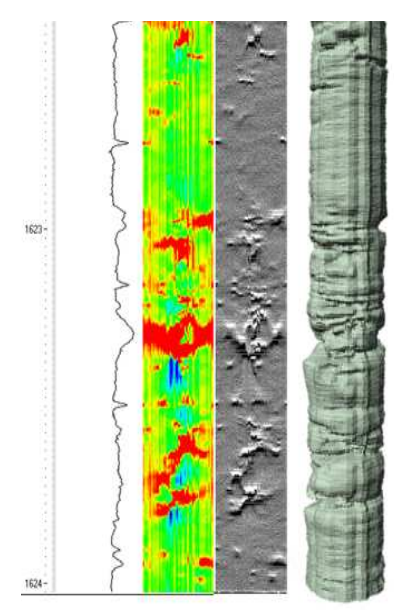

c

Fig. 3 The 3D image and its unfold graph of the casing. a) casing shape and casing corrosion, b) perforation holes, c) casing damage at perforation zone.

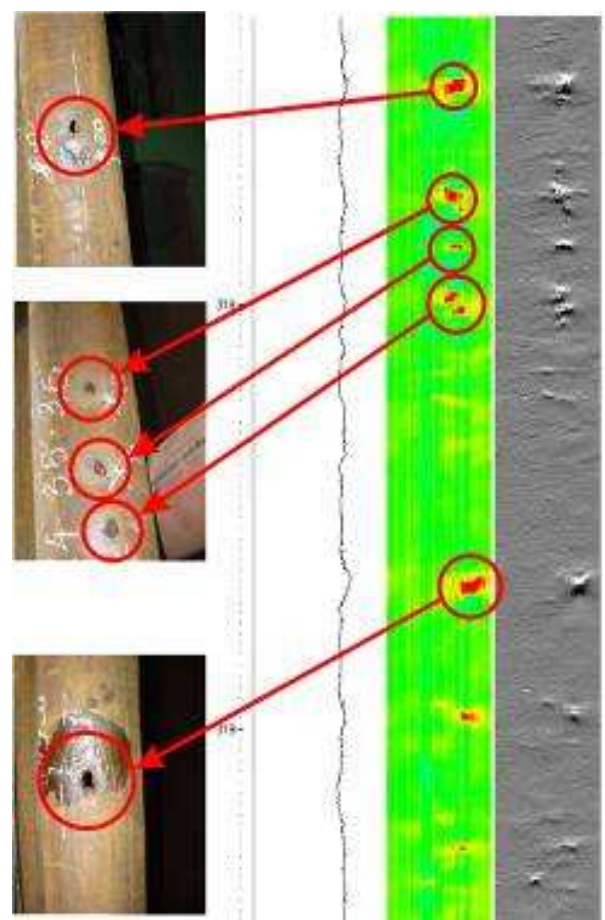

Fig. 4 Comparison of the inspection results of EMIT with the actual casing pulled out of well. 


\section{Applications}

The following contain some examples of the EMIT from the oilfield. The examples show "high resolution" of the EMIT. Figure 4 is a test well of the assignment. After finished the EMIT logging, the casing are pulled out of well. The response of the hole in the imaging from interpretation result corresponds with the actual hole in the casing wall. Figure 5 show us the pits, holes and perforation interval in the casing wall. Figure $6 \mathrm{a}$ is a significant case, there was a big mistake when perforation finished. The designed perforation interval is $1595.2-1596.8 \mathrm{~m}$, but the actual perforation interval is $1596.4-1598.0 \mathrm{~m}$. The depth of actual perforation interval is deeper than designed interval, about $1.2 \mathrm{~m}$. Figure $6 \mathrm{~b}$ is the case of corrosion flaws on casing walls within the perforation interval. Figure $6 \mathrm{c}$ is a damage of sulcate type cased by drill pipe. Figure 7 is an uncompleted screw of the pipes in the collar. Figure 7a show incompletely tightened pipe at the casing collar and figure $7 \mathrm{~b}$ is a normally tightened pipe.

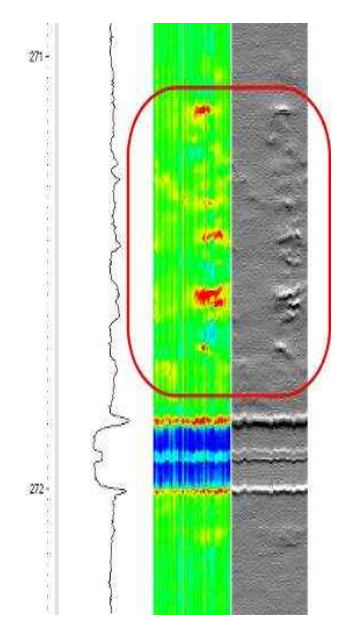

a

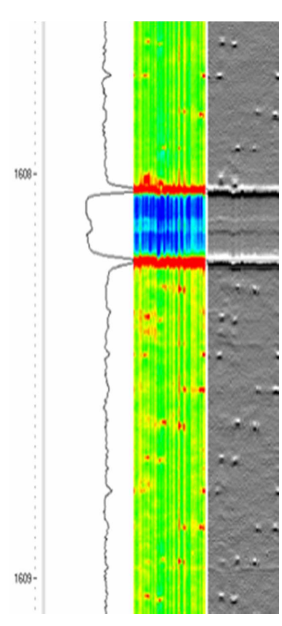

b

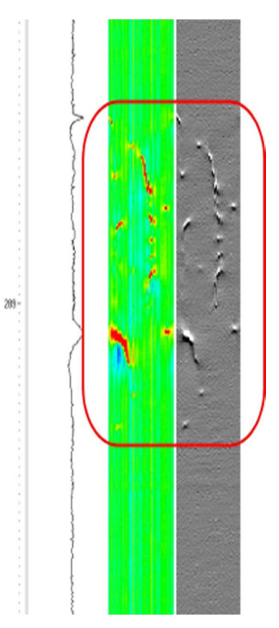

c

Fig. 5 According to EMIT data. a) highlighted intervals of corrosion flaws of the casing, b) perforations,

c) special holes.

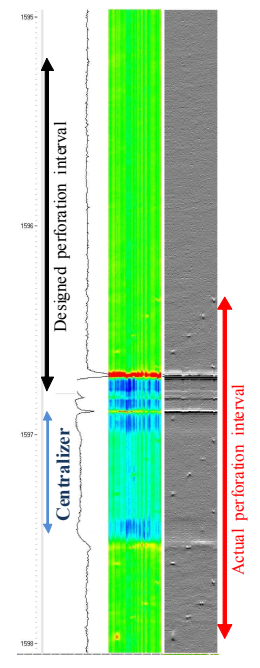

a

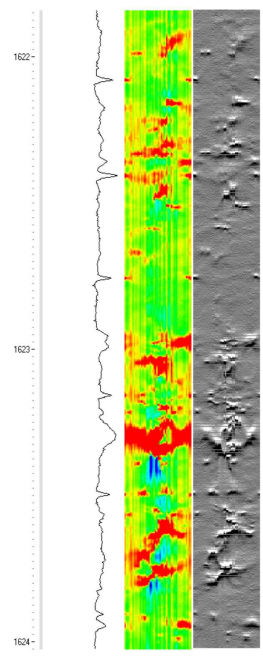

$\mathrm{b}$

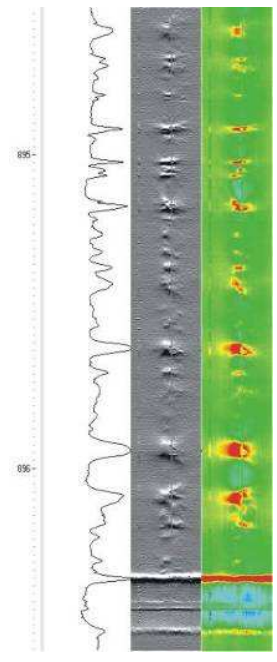

c

Fig. 6 The results of EMIT inspection in the casing well. a) determination of the actual perforation intervals with the designed ones, b) corrosion flaws on casing walls within the perforation interval, c) damage of sulcate type cased by drill pipe.

As has been described above, It is a very important to manage casing integrity in the safe operations of oil and gas wells. The EMIT is an effective tool to evaluate the technical condition of well. However, there is no universal method of inspection. When inspecting a well, it is advisable to 
use EMIT combination with other geophysical methods of casing inspection, such as thermometry, flow-metering, cement-bond logging, pipe profile-metering. Figure 8 is a good example for combination of EMIT, radiographic and thermometry. The position of fluid entry inspected by EMIT agree with radiographic and thermometry. This approach provides information to evaluate the whole well and its problem areas.

To expand the application of the EMIT technology, it is necessary to solve the following problems in the future:

1) To develop the evaluation of well technical condition, it must consider casing conditions, which includes calculations of life-time, corrosion rate, and the analysis of operation factors.

2) To work out a list of inspection parameters.

3) To setup a criteria of diagnosis defects.

4) To build a models for evaluation of well technical condition.

5) To perfect the EMIT in the area of casing damage.

We suggest to combine EMIT with other geophysical methods.

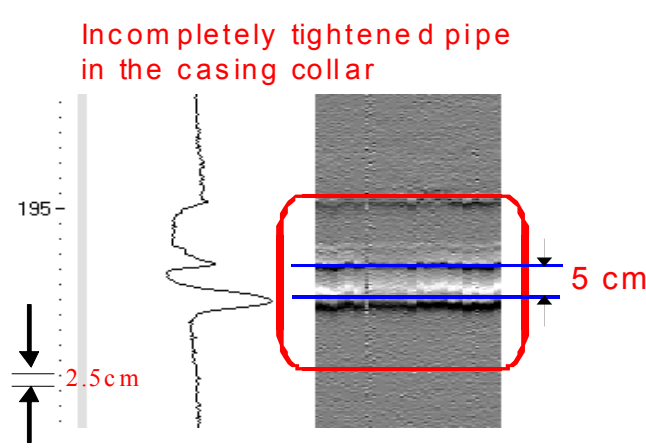

a

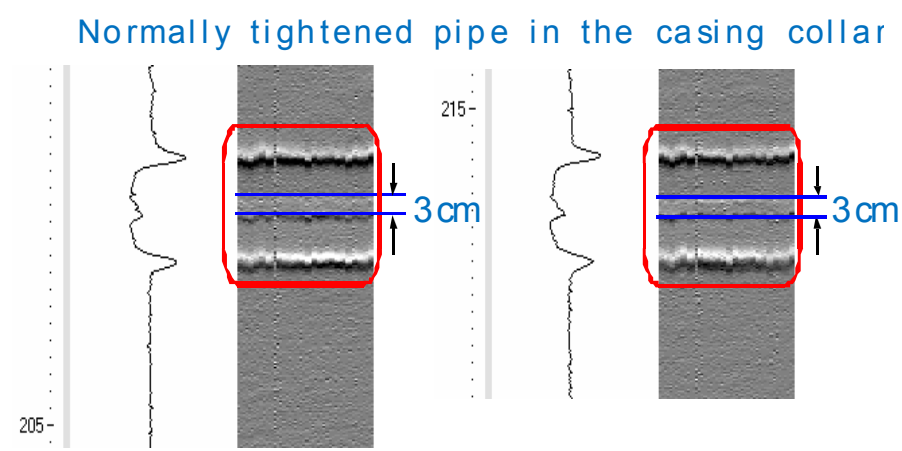

b

Fig. 7 EMIT data on measuring incompletely tightened pipes and normally tightened pipes in the collar. a) incompletely tightened pipe at the casing collar. b) normally tightened pipe at the casing collar.

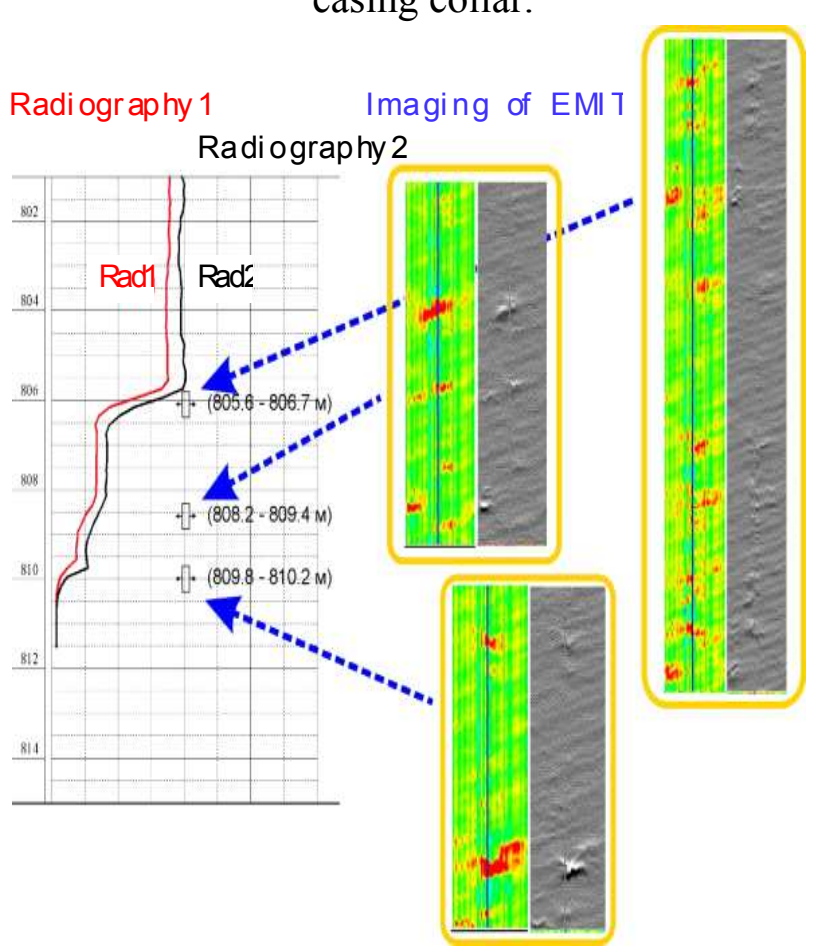

Fig. 8 The position inspection of fluid entry combine of EMIT, radiographic and thermometry. 


\section{Conclusion}

The results from the oilfield has shown that the EMIT has a "high-resolution". It can inspect different defects in casing well. The new EMIT is an effective tool to evaluate the technical condition of a well. It is advisable to use EMIT combination with other geophysical methods while casing inspection. The technology has been approved and tested, and the equipment has been certified, and the method has been recommended for inspecting of oil and gas wells.

\section{References}

[1] J.M.Edwards, S.G.Stroud, Mccullough Tool Co., New Electronic Casing Caliper Log Introduced For Corrosion Detection, Journal of Petroleum Technology, Issue August,(1966), p. 933

[2] G.Frisch, B.Mandal, Advanced Ultrasonic Scanning Tool and Evaluation Methods Improve and Standardize Casing Inspection, SPE Annual Technical Conference and Exhibition, 30 September-3 October, (2001), New Orleans, Louisiana.

[3] X.F. Zhong, Y.X. Wu, et al., Ultrasonic tomography and its applications in oilfield. J. Zhejiang Univ SCI, 6A(12) (2005), p. 1420

[4] D.R.Fincher, A.C.Nestle, Fincher Engineering Co. A., Review of Corrosion Monitoring Techniques, SPE Symposium on Handling of Oilfield Water, 4-5 December, (1972), Los Angeles, California.

[5] X.F. Zhong, Y.X. Wu, et al., The Multi-Pipe String Electromagnetic Detection Tool and Its Applications. ICEMI (2007), IEEE PRESS, p. 423

[6] Thilo Michael Brill, Jean-Luc Le Calvez, Cindy Demichel, et al, Quantitative Corrosion Assessment with an EM Casing Inspection Tool, SPE/DGS Saudi Arabia Section Technical Symposium and Exhibition, 15-18 May (2011), Al-Khobar, Saudi Arabia.

[7] V.G.Fadeev, A.A.Abakumov, V.V.Bazhenov, S.A.Dolgikh, Technology of the magnetic introscopy for defectoscopic survey production casing wells, a collection of abstracts $\mathrm{V}$ Russian-Chinese Symposium on geophysics, Moscow, (2008), p. 89 
Electrical Insulating Materials and Electrical Engineering

10.4028/www.scientific.net/AMR.546-547

New Electromagnetic Imaging Tool Introduced for Corrosion Detection

10.4028/www.scientific.net/AMR.546-547.19 